\title{
The Impact of Pandemic COVID -19 in Workplace
}

\author{
Dr. Meenakshi Kaushik ${ }^{*} \quad$ Neha Guleria $^{2}$ \\ 1.Professor and Head of the department, School of Commerce and Management Lingayas University, Faridabad \\ (Haryana)- 121002, India \\ 2.Research Scholar, School of Commerce and Management, Lingayas University, Faridabad (Haryana)- 121002, \\ India \\ *E-mail of the corresponding author: kaushikmeenakshi36@gmail.com \\ hod.management@lingayasuniversity.edu.in
}

\begin{abstract}
COVID-19 has become a huge worry for the Globe. The social and economic impact of COVID-19 pandemic will be far reaching and devastating for all. In this globally connected world, every country will get impacted by the devastation caused by the pandemic. The COVID-19 is likely to lead to certain permanent or long-lasting. By the time, when the pandemic ends, we will probably see a new world, a new lexicon, a new social norm with far reaching economic and social destruction. When COVID-19 outbreak started spreading across the world, thousands of people started facing severe health issues and death rates increased. The only way to stop the spread of the pandemic was to stop all social and economic activities in the affected countries for indefinite period of time. This led many countries to impose complete lock-down all across the globe which is still going on going on. In such a scenario all business activities, across all industries were completely stopped. The lockdown impacted various sectors in varied degree. For example, the airlines, hospitality, hotel, manufacturing industry is totally stopped and will take a long time to come out of this situation, if at all. Millions of people in these sectors are likely to lose jobs in these sectors. COVID-19 pandemic caused enormous disruption in businesses, which will take years to recover, if at all. The disruption is likely to lead to permanent shut down of many businesses, unable to bear the financial losses and disruptions caused by the pandemic. To get over the current situation, companies are trying to run offices and administration jobs through "Work from Home" mode. Companies are trying to cope up with economic turbulence caused due to COVID 19 through the usage of disruptive technology by working from home concept. Earlier work from home was an acceptable business practice only in IT and Technology sectors. However, other industry sectors were reluctant to adopt WFH as a good business practice. The biggest business change that we can see today, forced by the global spread the pandemic, is that many companies have been forced to implementing Work from Home mode for their employees. During the last 2 months, companies have found significant benefit in the WFH. Most companies, going forward, are looking at WFH as an integral business model. The WFH mode is helping some industries and functions in keeping its operations going, in a limited way. This research paper analyses the positives and negatives aspects of work from home concept as during this COVID-19 crisis, people working on WFH, are compelled to live in social isolation and emotional distancing. One can balance the responsibilities of work-life domains, especially when life domain needs as much attention as to work, during these difficult times. The study has focused on the impact of COVID-19 virus pandemic on working life of employees. This research paper also emphasizes that how employers as well as HR managers are required to think out of the box and bring forth best practices as well as redefining HR roles during any adversity . This research paper will also give light on few important issues such as People-Connect, adoption of a system of Skilling, re-skilling, Up-skilling and multi-skilling people about technology, design thinking, storytelling, analytics, Artificial intelligence to prepare our workforce to become more competent and talented by enhancing their skill set.
\end{abstract}

Keywords: Work from Home, COVID-19, social distancing, lockdown, people-connect, re-skilling, multi-skilling, up-skilling, technology disruption.

DOI: $10.7176 / \mathrm{EJBM} / 12-15-02$

Publication date:May $31^{\text {st }} 2020$

\section{Introduction}

The 2019-20 crown infection pandemic is a ceaseless pandemic of corona infection ailment 2019 (COVID-19) realized by a corona infection (SARS, CoV-2). The flare-up was recognized in Wuhan, China, in December 2019. However, because of initial mishandling by multi-lateral bodies like WHO, people were allowed to travel globally which led to spreading of the COVID-19 across the world, thus causing pandemic of epic proportion. It was only in March 11th, 3 months after the initial detection of COVID 19, that the WHO declared it as a pandemic. By that time, the damage is already done; the virus had spread across many countries. As on 1 May 2020, more than 3.27 million instances of COVID-19 have been accounted for in 187 nations and regions, bringing about in excess of 234,505 deaths. More than 1.02 million individuals have recuperated from the disease. The first instance of somebody experiencing COVID-19 can be followed back to 17 November, as indicated by media provides details 
regarding unpublished Chinese government information. Chinese specialists had distinguished at least 266 individuals who got the infection a year ago and who went under clinical reconnaissance and the soonest case was 17 November - weeks before specialists declared the development of the new virus. For around one month after that date, there were one to five new cases detailed every day, and by 20 December there were 60 affirmed cases. In India, on 1 May 2020 (8:00 AM), as per the Ministry of Health and Family Welfare, a sum of 35043 COVID19 cases, (counting 111 outside nationals) have been accounted for in 32 states/association regions. These incorporate 8888 who have been relieved/released, 1 who has relocated and 1147 deaths. Clinical confinement of every single affirmed case, followed by home isolation of the contacts is continuous. Without an intercession, all things considered, there will be all the more genuinely sick individuals than we have the assets to think about. We can't impact organic properties of the infection; however, we can change the measure of contact we have with one another by maintaining social distancing. The need of social distancing gave rise to the concept of "working from home concept (WFH)" for corporate for keeping alive the working spirit of the employees. Work from home (WFH) is where the individuals can do their job from home through massive use of digital platforms. After this pandemic, business trends have completely changed and majority of business activities are performed through mobile, or other digital platforms. Artificial Intelligence, analytics all have changed the way companies used to run and functioning a business. During the current COVID-19 pandemic, in order to keep the operation going, businesses are forced to move to work from home mode for their employees, wherever possible. Every action has its pros and cons; same is the case of the adoption of Work from Home concept. If on the one hand, COVID-19 impacts business organization and economy in a negative way, this has also forced companies to look at alternative way to run operations through remote connection and adoption of digital technology. WFH has been a positive change to many people as it keeps employees productive while helping in maintaining work life balance. However, it is not all about to balancing life, but facing all the challenges positively to perform and bring forth productively as the scenario demands. Work from Home is beneficial in some points but also having drawbacks too. The present trend of COVID -19 crisis has also forced employers and HR personnel /Consultants to re-think, re-design and think out of the box and bring forth the best practices for running their businesses and industries. The challenge for $\mathrm{HR}$ is to continue to develop employees who are innovative, proactive, committed and dedicated to their employer, while remaining positive and productive in this difficult situation for success in the current circumstances.

\subsection{People Connect}

When lockdown was declared, organizations and industries started facing issues mainly on people-disconnect issue front as they went back to their villages. $80 \%$ people from organized sector went homeless overnight. Even now the biggest challenge for HR is to get back people to work as soon as possible. Apart from reaching beyond culture and trust, there are technical challenges to be faced. Not every home has an office or quiet workspace. So, the need of the hour is to reconnect with those people either by calling them via phone, asking their wellbeing, assisting and ensuring their wellbeing on phone. Many people do not possess sophisticated systems along with headsets, video cameras, high-speed connectivity, and the skills to manage all. Assisting such people, by giving them training about the technology as well as availing all the facilities to such employees. At the same time, many people right now are not only trying to do their own work, but they are trying to help their families cope and keep their children on a course of study. Lastly, on the challenges front, there are very real social and psychological concerns. During an adversity such as what we are facing right now, there are worries for almost everyone. To overcome these concerns, it is helpful to deploy the tenets of positive psychology, including resiliency, positivity, and psychological safety. Employers can play an important role in bringing such tactics to the virtual workspace in which their employees operate.

\subsection{Maintaining Normalcy}

So how do we overcome these challenges? People crave routine. Therefore, it is important that employers lay the groundwork for employees working from home to establish and maintain normalcy-whatever normal may mean under current circumstances- including taking time out of the day to tend to love ones. Part of laying the groundwork for normalcy includes establishing and agreeing upon goals, along with regular measurement of the progress of goal achievement. This is followed up by aligning weekly priorities and milestones so that employees stay focused on the most important things. Then, it is all about communication. Management also need to check in often and consistently to learn how people are dealing with transitioning to remote work. It is also critical to give employees a place to feel seen and heard. Now is also an excellent time to step up recognition programs. Peerto-peer and manager to subordinate recognition can help motivate the team to stay on track to together achieve the organization's goals. There is no better time to express gratitude. Telecommuting and working from home have been hot topics for several years now. According to a recent study conducted by Flex jobs, the number of people working from home at least part time has increased by $44 \%$ over the last five years. And since Coronavirus has struck, working from home has become the de facto standard for most office workers. Even call centre and 
customer service positions have moved to home offices.

\subsection{Social Distancing}

While employing a home-based team presents challenges; there are also benefits to the practice beyond the immediate need for social distancing. A home-based workforce saves the company money through lower overhead and reduced drain on energy resources. From a macroeconomic perspective; fewer people commuting mean a reduction in pollution and usage of fossil fuels. Just in the few short weeks of the pandemic crisis so far, pollution levels have been measured as falling meaningfully over parts of China and Europe. Benefits also include productivity gains. Adam Grant's Nick Bloom experiment showed that if you let call centres work from home, they're 13\% more productive. They have the flexibility around where they work, when they work, and how they work, and they don't feel like they're being micromanaged. Perhaps most importantly, offering home-based work improves employee morale. People who no longer must deal with lengthy commutes have more time to devote to family and work-life balance. No one possesses an infallible crystal ball to predict the timing of the end of the current crisis, or what life will be like following the crisis. However, organizations now more than ever before will have had the opportunity to experiment with a geographically dispersed workforce and will gain tremendous insight into how to do so effectively. For successful implementation of WFH mode, companies need to take care of the following.

\subsection{Infrastructure}

Companies will need to ensure that employees are well equipped to deal with remote working practices. Some firms already do this by offering them an allowance to set up a home office where they can work uninterrupted, should the need arise. This allowance can cover a variety of needs - be it a high-speed internet connection, power backup, necessary gadgets and devices, or even office equipment like desks and ergonomic chairs. People who do not have the required space or facilities at home will need to be provided with an alternative too. Perhaps companies can do this by having co working spaces across the city that will function as work hubs.

\subsection{Collaboration}

Collaboration is one of the biggest challenges that companies face, when they allow employees to work from home. Effective collaboration goes much beyond just ensuring that people log in for meetings and calls when they are supposed to. Spontaneous collaboration has a big role to play in how people innovate and come up with creative solutions - and this should be taken into account when crafting a good remote work strategy. Companies will need to provide a good collaborative framework, consisting of meeting tools, chat apps and data sharing software. Encouraging video calls and promoting casual interactions can go a long way in reducing the sense of isolation that people report when they work from home. Suggest to interaction with site teams on every Monday by key officials of company one by one.

\subsection{Security}

Firms that deal with a lot of confidential client information will have to ensure that employees are working from a secure environment when they work remotely. The first step here is to install the right security software and enable automatic updates, not just on laptops, but also on smart phones or any other personal devices that employees might use to access client data. Mandating device encryption is another criteria and way to ensure that there will be no security breach, even if the device is lost or stolen. Most importantly, firms will need to offer the right training, so that people across the board are able to spot suspicious activity and report malware, cyber-attacks or phishing attempts.

\subsection{Policy framework}

In the past, people hesitated to work from home because of the perception that they will be penalized when it comes to promotions and bonuses. In firms where working remotely was largely seen as an exception, this perception was probably accurate. An employee may have had to ask for permission from their managers, or negotiate for the benefit on a case-by-case basis. In such an environment, those using this privilege too frequently may certainly have found themselves at a disadvantage. Now, companies who want to embrace an office-less future will have to put in the effort to build a culture of remote work. Ensuring that managers do not harbor a negative bias towards remote workers can be a great start. Having fair feedback policies and transparent appraisal processes are other ways to bring about this change. Suggest to follow 5 days working in a week with flexibility of working hours like $10.30 / 11 \mathrm{AM}$ to $4 / 4.30 \mathrm{pm}$ during present scenario as company can adjust such loss of working hours in normal days throughout year

1.8 Emotional well-being

There's one oft-overlooked aspect of remote working that the recent COVID-19 outbreak has brought to the fore 
— that of loneliness and isolation. If remote working is to be normalized over time, companies will need to find ways to get around this. Innovative use of technology can help to some extent. The culture of having video hangouts every week is one great option, where team members can log in remotely to play games and catch up with colleagues. Managers can ensure that work achievements as well as employees' personal milestones like birthdays and anniversaries are shared and celebrated with everyone on the team. Companies can also use technology to gamify the little things - like the number of steps employees take through the day. A spot of friendly competition or a shared joke or two can make all the difference when one is working alone all day Studies have shown that when employees work in familiar, comfortable environments, there is a higher possibility of a boost in their performance. Given the current situation with corona virus, employers have no option, but to trust their employees. Working from home has merits for both, employers and employees. For employers: having a WFH program saves on office space and other office expenses, thereby creating opportunities to utilize capital resources for expanding their business to new avenues. For employees, in major cities where commuting consumes a major time, working from home would be a lucrative offer, working from home would also suite someone whole suffers social anxiety and loves to work in isolation, just like the virus currently demands of you. With its set of merits and challenges, remote working due to this pandemic has definitely instilled a sense of belongingness amongst the office colleagues and has given an unanticipated break to many, from daily commute and work routines.

\section{Need of the Study}

The 2019-20 crown infection pandemic is a ceaseless pandemic of corona infection ailment 2019 (COVID-19) realized by a corona infection (SARS-CoV-2). The flare-up was recognized in Wuhan, China, in December 2019. However, because of initial mishandling by multi-lateral bodies like WHO, people were allowed to travel globally which led to spreading of the COVID-19 across the world, thus causing pandemic of epic proportion. It was only in March 11th, 3 months after the initial detection of COVID 19, that the WHO declared it as a pandemic. By that time, the damage is already done, the virus had spread across many countries. There is a work up need to focus on maintaining a better work life balance by maintaining a balance between personal life as well as professional life by following issues taking into consideration. The need of social distancing gave rise to the concept of "working from home concept (WFH)" for corporate for keeping alive the working spirit of the employees. Work from home (WFH) is where the individuals can do their job from home through massive use of digital platforms. After this pandemic, business trends have completely changed and majority of business activities are performed through mobile, or other digital platforms. Artificial Intelligence, analytics all have changed the way companies used to run and functioning a business. During the current COVID-19 pandemic, in order to keep the operation going, businesses are forced to move to work from home mode for their employees, wherever possible. Every action has its pros and cons; same is the case of the adoption of Work from Home concept.

\section{Objectives of the study}

- $\quad$ To interpret the basic concept of work from home during COVID-19.

- $\quad$ To study the present scenario of work from home.

- $\quad$ To analyse the factors effecting work from home for employees.

- To examine the impact of COVID-19 on work performances of employees when working from home.

\section{Research methodology}

This research paper aims to present a deeper insight to analyze the impact of COVID -19 in work place during this period of adversity and what all measures are required by employers and HR personnel to be take into consideration for proper organizational functioning to get over the current situation of COVID -19 crisis or in any adversity. companies are trying to run offices and administration jobs through "Work from Home" (WFH-Mode) and how authentic leaders are driving the new normal by bringing forth new concepts of People-connect, usage of disruptive technology and becoming smarter through virtual acclimatization and virtual relationship management and HR plans to make an employee's home function as a node to an office hub -smarter technology, processes and policies are a big step in that direction.

This research paper is basically descriptive and analytical in nature. Data collection is based on primary data and secondary data .Primary data is collected from the telephonic interviews and questions asked from the HR consultants and few industry top level people in HR positions and working professionals. The secondary data is based on the current data and scenario. Secondary data is collected from various research papers, articles and publishing of 2019-2020 year according to the need of the study.

5. The positive side of Work from home concept: Here are some of the positive points of work from home discussed as below-

- In case of women, it is very difficult to maintain a balance between work and home responsibilities. Work from home concept plays a vital role for women as doing work from home helps women to coordinate 
the dual responsibilities of managing home and work place. Due to the impact of COVID-19, all the family members have to stay. Consequently, the responsibilities of working women are on higher side. To get a work space and time management by working from home is difficult task in the present scenario. But all is a matter of proper time management and maintaining work life balance and being more agile, proactive, rational, dedicated and committed and maintaining work life balance and time management.

- One of the biggest advantages of WFH is the time saved in commuting to and from office. Regardless of whether one's office is close or far, one needs to go out, be stranded in rush hour gridlock and bear the temperature outside. But during work from home, travelling time is zero and that time can be invested in work or life domain for the productive results during the lockdown situation. One can invest this time in health also to keep oneself fit and fine. A peaceful mind boosts energy to perform well.

- Because of COVID-19 pandemic everyone is staying at home. Children are not going to school. Working individuals have to manage their work space at home if more than one individual is working from same home. Though work from home is more challenging when it comes to time management and maintaining a balance mentally and physically while performing each and every task related to household chores and workplace amicably and peacefully.

- Technological advancements support Work from Home in a significant way. It is because of technology available with us currently, one can easily connect with his/her work by staying at home. But one should be aware about the use of technology. So, Employer and HR need to manage workforce in this unprecedented time. HR needs to rethink again by anticipating what talents and skills are needed.

- Restructured and redefined work roles coupled with reskilling of resources is the need of the hour. It is important for companies to evolve and change to ensure that the workforce is rebooted and get smarter through virtual acclimatization and virtual relationship management.

- HR needs to plan how to make an employee's home function as a node to an office hub - smart technology, processes and policies are a big step in that direction. While employing a home-based team presents challenges, there are also benefits to the practice beyond the immediate need for social distancing. A home-based workforce saves the company money through lower overhead and reduced drain on energy resources.

- From a macroeconomic perspective, fewer people commuting means a reduction in pollution and usage of fossil fuels. Just in the few short weeks of the pandemic crisis so far, pollution levels have been measured as falling meaningfully over parts of China and Europe.

- Benefits also include productivity gains. Adam Grant's Nick Bloom experiment showed that if you let call centres work from home, they're $13 \%$ more productive. They have the flexibility around where they work, when they work, and how they work, and they don't feel like they're being micromanaged. Perhaps most importantly, offering home-based work improves employee morale. People who no longer must deal with lengthy commutes have more time to devote to family and work-life balance.

- No one possesses an infallible crystal ball to predict the timing of the end of the current crisis, or what life will be like following the crisis. However, organizations now more than ever before will have had the opportunity to experiment with a geographically dispersed workforce and will gain tremendous insight into how to do so effectively. Home-based work can be incredibly successful for teams. Here are a few tips to consider: Establish goals, Conduct regular manager and employee communication, Provide space and virtual tools to allow employees to feel seen and heard, Start the first $2-5$ minutes of every meeting talking about non-work-related items to deepen trust and connection, Ensure recognition is rooted into the rhythms of the work week, Given the many benefits of home-based work, it is likely that it will become far more accepted as the new adverse COVID -19 situation is prevailing.

5.1 The negative side of the work from home concept: Following is a list of disadvantages of work from home concept -

- Since one working from home, one can get disengaged from associates and bosses.

- Working from home may cause numerous interruptions. One needs to go and attend to visitor, cook for family, clean home and oversee children.

- Work from home makes an employee detached from his/ her company and make an employee lack the community feeling and attachment to his / her company.

- It needs self-motivation commitment and devotion and being proactive, agile and resilient on behalf of the employees otherwise leading to un-productivity. Here HR plays a pivotal role to bring forth the concept of "People -connect".

- WFH creates differences in culture with employees who work at office.

- WFH does not foster communication and kinship with company.

- Due to lack of psychological association with one's company, there is low reliability and retention of employees. 
- It is difficult to manage and maintain accountability of employees working from home. It leads to significant loss of productivity and motivation.

There are several challenges that the work-at-home (WFH) model presents to both employees and employers even in the best of times. A study published by Rensselaer Polytechnic Institute prior to the onset of Coronavirus indicates that those who work from home on a regular basis while eligible to be considered for promotions are likely to suffer from overall lower pay increases than those given to on-premises employees. Some of the challenges that we are seeing now stem from employers that typically don't support a geographically dispersed workforce. Managers and supervisors may be ill-equipped to manage staff remotely. In general, management style and culture are deeply ingrained and tend to fit into either the McGregor Theory X or Theory Y model. "X" management believes that workers need to be closely watched to keep them on task, while "Y" management believes that if you hire the right people and give them the tools that they need, they will invariably do the right thing. The "Y" style conveys a culture of trust; trust is the key ingredient for success in the current circumstances.

\section{Literature review}

On 12 January 2020, the World Health Organization (WHO) affirmed that a novel corona virus was the reason for a respiratory sickness in a bunch of individuals in Wuhan City, Hubei Province, China, which were accounted for to the WHO on 31 December 2019.

The main instance of the 2019-20 crown infection pandemic in India was accounted for on 30 January 2020, beginning from China.

Corona infection is a group of infection or irresistible maladies that can cause various kinds of disease among human including basic cold to sewer perilous. We called it as crown infection since its shape resembles a crown. Adhere to all the directions given by the Government to help them as till now this is the main Vaccine we have. We ought to connect just with our relatives and attempt to do however much as could reasonably be expected work from home even Government assume noteworthy job to supply all the fundamental things to the entryway steps.

\subsection{Lockdown}

On 22 March 2020, India watched a 14-hour deliberate open time limitation at the instance of the PM Narendra Modi. In light of the COVID-19 pandemic, National governments have applied lockdown limitations to diminish the disease rate. Expanding concerns are emerging on the monetary results of lockdown and how it can disproportionally influence the more fragile and the less fortunate economies. The force of the abrupt stop prompted by the Covid-19 episode produces impacts which are like those delivered by an enormous cataclysmic event. The worldwide lockdown is likely to lead to overall drop in efficiency and compromise monetary development of economies, for a long time.

\subsection{Social distancing}

It is the act of expanding the space between individuals so as to diminish the opportunity of spreading COVID-19 pandemic. As per the CDC, dispersing of $6 \mathrm{ft}$ away declines the spread of COVID-19. The degree to which work can be led from home in this manner is a key factor deciding the financial results of social distancing arrangements. Singular activities incorporate working remotely, evading open transportation, and remaining at home. Network wide measures incorporate progress to internet instructing, organizations incidentally shutting, and the far reaching commitment of media transmission. Numerous nations are executing radical proportions of social distancing to tame the spread of COVID-19. These measures regularly include exclusion of work environments to confine relational contact. While they are set up, work can possibly proceed on the off chance that it tends to be directed from homes.

\subsection{Economic recession}

The current pandemic is likely to lead economic recession of the kind that was seen in 1918 great depression. In fact, there are indications that the current recession may be even worse than the great depression. The economic recession caused by the COVID 19 pandemic is likely to reverse the poverty alleviations achieved in last decade and push back millions of people back to abject poverty. Governments are sending individuals home, and only a few industries which are connected to the essential services, are permitted to work. As the pandemic keeps on spreading all over the world and nations are conceivably confronting the most noticeably terrible monetary downturn in decades.

\subsection{Work from home}

"Work from Home" is not a new term to use in nowadays. It has been around for longer than 10 years. The COVID19 pandemic has prompted greatest number of representatives comprehensively bound to work remotely. The idea has been called numerous things including Telecommuting and Remote Working. In any case the COVID-19 pandemic out of nowhere made this an impulse instead of a choice. The Indian government commanded that 
corporate permit however many as could be expected under the circumstances of their workers to work from home - and set a model inside its own dividers. The term work from home came in to prominence in 1970s. Work from home gives an adaptable working hour to the individuals just as the work for the business is finished easily. Work from home is useful to conveying work life parity to the representative, and furthermore parallel causes the organization to complete the work. Work from Home facilitates flexibility in working hour and working environment. Work from Home leads to spend quality time with the family and close ones. Covid-19 constrained work-from-home on organizations. Work from home may remain much after the pandemic alarm blurs. HR heads of significant organizations agree that the relative success of work from home is one of the silver-lining covering in the entire disaster. Managers and workers profit by working from home even in typical occasions. Throughout the most recent few weeks, organizations have been in a putting out fires mode to set up the IT backend, which has been the most critical bottleneck so far in grasping virtual work environment. Organizations are set to rethink seating at workplaces as per social separating standards, present move based work, go virtual with gatherings, increase cleaning convention with visit sanitization and arrangement of hand sanitizers, and reintroduction of access cards instead of biometric. The post-Covid-19 work environment will likewise have an enormous number of representatives telecommuting. Organizations likewise anticipate that the utilization of office workspace should be radically not the same as pre- COVID time, where advancing the utilization of office space was fundamental.WFH capability of different employments and areas to configuration proper approaches and practices for managing the present emergencies and to design future change. For instance, the administration needs to configuration bolster strategies for areas and laborers. A one size fits all arrangement will be less successful in moderating the hazard ideally. Thus, firms need to check how they contrast with different rivals in their part. The suggestions for laborers are additionally complex regarding efficiency, preparing, and generally speaking prosperity. These improvements will have enduring effect and will require close observing for educated dynamic. The circumstance may stretch out for a considerable length of time or significantly more. In any case, it is an extraordinary open door for a way of life change. There will be no racing to venture out from home and skipping breakfast so you won't miss the train. Some organizations don't advocate for work from home as they accept individuals can't work without supervision. Rather, they embraced a controlling and smaller scale the executives' culture. On the opposite finish of the scale, the difficulties of group joint effort and correspondence become clear when colleagues are scattered in disengagement. They likewise feel continually appended to work while diverted by things at home. To a few, it might appear recently discovered opportunity, yet alongside it comes duty also. In any case, the greatest drawback is this is putting undue burden on family broadband associations. Workplaces for the most part have better data transfer capacity and business systems are intended to take load. However, when out of nowhere a noteworthy number of individuals begin signing in from home, blackouts follow. Web has turned sketchy. To guarantee efficiency doesn't endure, a few organizations are depending on applications intended to keep a mind those signing in remotely. Office isn't tied in with sitting at your work area and completing a task. It additionally includes various associations over espresso or tea, on occasion in gatherings, individual holding and even casual conversation that are known to take worry off individuals and lift efficiency. A few organizations are attempting to impart that pleasant component in their work-from-home understanding.

\subsection{Cyber security}

Representatives ought to speak with associates for authentic issues utilizing IT gear given by managers. There is regularly a scope of programming introduced out of sight of organization IT that keeps individuals secure. In the event that a security episode occurred on a worker's individual gadget, the association - and the worker - may not be completely ensured. New COVID-19 themed phishing tricks are utilizing dread, snaring defenseless individuals and exploiting work environment disturbance. Thus, the individuals telecommuting ought to promptly get taught about their digital security and cyber security bombing which the worldwide cybercrime harm costs as much as twofold before the current year is over. Organizations probably would not have an all set suite of instruments for those who are working from home. On the off chance that you do not have a home office, do as much as possible to make a specially appointed, be spoke space solely for work. Not having a well-prepared home office space when people start working from home can cause a transitory lessening in profitability. So as opposed to lying in bed with a PC, have a go at something progressively purposeful. The fix could be something as basic as moving an end table into a corner far away from interruptions, thudding down PC and sitting in an upstanding seat, similar to you would at your office work area. There are two kinds of working from home: present moment or intermittent work from home and changeless or all day-work from home. With COVID-19, it is not satisfactory to what extent individuals will be at home, which represents extra issues. Beyond a shadow of a doubt, these are upsetting occasions. Friends and family are battling to get rid of this pandemic. Yet, the more exertion you put into speaking with associates, the better possibility you have of dodging sentiments of detachment, which can prompt discouragement. It is anything but difficult to be worried or discouraged nowadays. There is a need of setting up standards or some likeness by keeping up the spirits. 


\section{Discussion and analysis}

1. Work from home is not as easy as it seems to be. That requires full dedication towards work activities to perform well. The concept also demands to focus on work schedule. There is a need to set limits between the domains of home and work while following the concept of working from home.

2. No doubts, there are ample benefits to grab by working from home. But on the same side that puts a person in to a comfort zone which leads to laziness and lots of distractions. Time management is another challenge to settle on. Work from home may make it simpler for employees to offset their work obligations with their own life and family jobs (e.g., thinking about kids or old guardians). A few associations embrace work from home for ecological reasons, as work from home can lessen blockage and air contamination, with fewer vehicles on the roads.

3. Employers as well as HR need to play a very pivotal role in creating a bond with the people under "People connect 'concept and need to connect people from grass root level whom they have always ignored The term has come to re-imagine HR as a stakeholder management during COVID-19 period they really need to realize this fact very seriously that money is not everything but to create a positive bond with them .So HR needs to perform multiple role when it comes to people related.

Skilling/ Reskilling/ Up-skilling - COVID period has made HR to rethink on certain issues regarding motivating, inspiring and training and developing the people and adoption of a system of imparting skilling (learning new skills for being competent in upcoming days, adversity or adversity or any crisis); up-skilling (learning current tasks more deeply); as this is the need of the hour to learn and understand new technology as well as manage relationships to fit into the changing scenario and economic landscape. People need to be updated on technology, design thinking, analytics, storytelling, and artificial intelligence etc. people at grass root level and working at lower profile are required to be trained on accomplishing their tasks and reporting about their developments to their supervisors either by mobile or any other platform. So, this way, making people competent and multi-skilled in a variety of ways and enhance their skill sets.

\section{Recommendations}

1. Without technological advances it is difficult to work from home. One should have good hand in technological uses. Availability of technology is highly demanded to fulfil the job at staying home. There is a need of laptop, desktop, software, a good internet connection, webcams for video conferencing and knowledge to use all that to accomplish the job.

2. There is a need of separate working environment at the home. Disturbances may lead to poor performance. A separate workplace boosts the concentration level and maintains the focus on a particular activity.

3. Good internet connectivity and its speed are absolutely necessary. Interruption causes breakage in job activities and concentration, delays and wastage of time.

4. One should follow the workable schedule while working from home. Some organizations having fixed working hours during that particular span there is availability of all the employees or teams. Some other provides flexibility in working hours. So as per the demand its required to work on with specific schedule.

5. A routine plan is highly recommended while work from during this pandemic. Everything should be scheduled in an effective manner. Only then effective results will come out. Otherwise pending work and incomplete job task may lead to frustration or will increase the stress. Everything and every activity on right time and right place within in the four walls is the mantra to follow, which will reduce the chaos and turns high productivity.

6. If following a routine plan then it requires proper time management as well. As you wake up in the morning, you should ready with the day plan decided with time limits. Late night sleeps and late waking up next morning can affect the routine of the coming day ahead. An effective time management provides you time for self-care. Thus, a person can exercise or meditate, and spend time for hobbies too. That keeps an individual entertained and busy all the day.

7. In every human life there are list of priorities which differ from person to person. During this pandemic and lockdown by staying at home all the time does not mean to divert from the focus. That is the time to pay attention towards which is highly demanding. If one is having poor health then that should be the first priority or if it is some another factor like as job performance, family responsibilities etc. so one should keep that in the top of the list.

8. While working from home due to COVID-19 pandemic, one should minimize the distractions at home. Otherwise it is difficult to concentrate on demanding activity. One point is that while reducing the list of your distractions, it is also important not to disturb your surroundings as well. Every family member of every house is staying inside together so better not to make high noises.

9. It is tough to minimize the distraction coming from children for working parents. Couple can set the time schedule for their job activities and mutually handling the children at home one by one too. A routine for children with napping time during day will help working parents. On the other side, in some case there are pets in the house, sometime creates distractions (like barking dogs). So in that case also it is important to feed them timely and spare some time for these creatures too. 
10. During this COVID - 19 crisis period it is also advisable to business organizations and industries to avoid job cuts and layoffs but some organizations are doing it in subtle manner and asking employees to resign which is not appropriate and need to get addressed and come out with certain positive solutions by creating a culture of learning, skilling, reskilling and up-skilling the people.Because of the pandemic there would be substantial job losses which could take up three to five years to recover. To be able to take full advantage of this reskilling, upskilling becomes critical for both employers and employees.

11. Maintaining a hygiene and social distancing and calling people at workplace in urgent cases on alternate days specially in manufacturing units HR to rethink on certain issues regarding motivating, inspiring and training and developing the people and adoption of a system of imparting skilling (learning new skills for being competent in upcoming days, adversity or adversity or any crisis ); up-skilling (learning current tasks more deeply ); as this is the need of the hour to learn and understand new technology as well as manage relationships to fit into the changing scenario and economic landscape.

\section{Conclusion}

Work from Home is a concept which is now going to be a permanent feature in the corporate world. The current pandemic situation has demonstrated that WFH is an effective business process to ensure continuity of business and also to provide work life balance to employees. It has significant economic and productivity benefit as well to organizations, if managed effectively. However, WFH cannot be seen as a panacea for all organization problems. It has to be used in a judicious manner to ensure employees are trained, motivated and harnessed to deliver the best towards business result.

\section{References}

AbuMezied, A. 2017. What role will education play in the fourth industrial revolution? World Economic Forum, agenda/2016/01. [Online] Available: https://www.weforum.org/agenda/2016/01/what-role-will-educationplay-in-thefourth-industrial-revolution/

Ahmad, T. 2020. Corona Virus (COVID-19) pandemic and work from home: challenges of cybercrimes and cyber security. Social Science Research Network, doi:10.2139/3568830, http://dx.doi.org/10.2139/ssrn.3568830

Atkeson, A. 2020. What will be the economic impact of COVID-19 in the US? : Rough estimates of disease scenarios. National Bureau of Economic Research, 26867.

Basu, D. S., Verma, P., \& Malviya, S. 2020. India inc resets workspaces for life after COVID-19 lockdown. The Economic Times, articleshow/75286800.

Bryan, L. 2020. Companies around the globe have rolled out mandatory remote work, whether you're a newbie or WFH veteran, here's what you need to do stay productive. British Broadcasting Corporation, worklife/article/20200312.

Transmission of corona virus disease 2019 (COVID-19). Centres for Disease Control and Prevention, March 4, 2020. http://www.cdc.gov/coronavirus/2019-ncov/prepare/transmission.html

Corona virus disease named COVID-19. 2020. British Broadcasting Corporation, news/world-asia-china51466362.

Corona virus vaccine within a year but it won't be 100\% effective. 2020. The Economic times, article/74704452. March 21, 2020

Gentilini, U., Mohamed, A., Orton, I., \& Dale, P. 2020. Social protection and jobs responses to COVID-19: a realtime review of country measures. Open Knowledge Repository, CC BY 3.0 IGO. https://openknowledge.worldbank.org/handle/10986/33635

Geissbauer, R., Vedso, J., \&Schrauf, S. 2016. A strategist's guide to industry 4.0. Strategy and business, summer2016 (83). https://www.strategy-business.com

Giovanni, B. Et. al. 2020. Economic and social consequences of human mobility restrictions under COVID-19, Social Science Research Network, doi:10.2139/3573609.http://dx.doi.org/10.2139/ssrn.3573609

SCTIMST scientists design super absorbent material for safe management of infected respiratory secretions. (2020). Indian Ministry of Science and Technology, April 9, 2020. Press information bureau.

Jaffle, E. et. al. 2020. The role of emergency medical services in containing COVID-19. The Amarican Journal of Emergency Medicine, doi: 10.1016/2020.04.023. https://doi.org/10.1016/j.ajem.2020.04.023

Linda, V. G., Vincelette, A. G., Schiffbauer, M.T., \& Kikoni, E. (2020). Hard times require good economics: the economic impact of COVID-19 inthe Western Balkans. Brookings, blog/future-development/2020/04/29/ https://www.brookings.edu/topic/global-economy/

Mani, D., \& Tomar, S. 2020. Work from home in the tome of COVID-19. The Hindu, 31207008. https://www.thehindu.com/opinion/op-ed/work-from-home-in-the-time-of-covid-19/article31207008.ece

Maynard, A.D. 2015. Navigating the fourth industrial revolution. Nature Nanotechnology, 10 (1005-1006). Doi: $10.1038 / 2015.286$.

Ruiyun, L. Et al. 2020. Substantial undocumented infection facilitates the rapid dissemination of novel corona 
virus (sars-cov2). American Association for the Advancement of Science, 368(6490), 489-493.

Singh, J., \& Jagandeep, S. 2020. COVID-19 and its impact on society. Electronic Research Journal of Social Sciences and Humanities, 2(1)/ 3567837 2020. https://ssrn.com/abstract=3567837

\section{Authors' Profile:}

\section{Dr. Meenakshi Kaushik (M.B.A, Ph.D.)}

Professor (Organizational Behavior \& Human Resources Management)

She is having more than 17 years of experience in teaching, training, research, and corporate in the area of Human resource management, Organizational development and leadership development. Presently she is associated with Lingayas University as a Professor (HOD) in School of Commerce and Management department, Faridabad (Haryana), India. She has completed her Ph.D. degree from Rajasthan University, Jaipur and her doctoral thesis entitled "A Study of Leadership Effectiveness in Women Executives in Context of Delhi Based Business organizations" has brought relevant theoretical and empirical imperatives on leadership development. She has worked as an academician at several reputed management institutions and universities in India. She has attended many conferences at national and international level and presented papers. Her research papers are published in many national and international refereed journals. She is the members of SHRM, AIMA, NHRD and DMA. 